\title{
Copper-catalysed amination of alkyl iodides enabled by halogen-atom transfer
}

\author{
Bartosz Górski ${ }^{1,3}$, Anne-Laure Barthelemy $\mathbb{(}^{1,3}$, James J. Douglas $\mathbb{C}^{2}$, Fabio Juliá $\mathbb{D}^{1 凶}$ and \\ Daniele Leonori® $1 \otimes$
}

\begin{abstract}
Despite the fact that nucleophilic displacement $\left(\mathrm{S}_{\mathrm{N}} 2\right)$ of alkyl halides with nitrogen nucleophiles is one of the first reactions introduced in organic chemistry teaching, its practical utilization is largely limited to unhindered (primary) or activated ( $\alpha$-carbonyl, benzylic) substrates. Here, we demonstrate an alternative amination strategy where alkyl iodides are used as radical precursors instead of electrophiles. Use of $\alpha$-aminoalkyl radicals enables the efficient conversion of the iodides into the corresponding alkyl radical by halogen-atom transfer, while copper catalysis assembles the $s p^{3} \mathrm{C}-\mathrm{N}$ bonds at room temperature. The process provides $\mathrm{S}_{\mathrm{N}} 2$-like programmability, and application in late-stage functionalization of several densely functionalized pharmaceuticals demonstrates its utility in the preparation of valuable $\mathbf{N}$-alkylated drug analogues.
\end{abstract}

$\mathrm{N}$ itrogen-rich molecules form the structural basis of almost every pharmaceutical and agrochemical lead, as well as many other high-value products like food additives and organic materials ${ }^{1}$. A large fraction of these chemotypes contain bonds between nitrogenated residues and saturated carbons, which makes the development of methods for $s p^{3} \mathrm{C}-\mathrm{N}$ bond construction integral to both academia and industry (Fig. 1a) ${ }^{2-4}$

One classical method is $N$-alkylation with alkyl (pseudo) halides using textbook $\mathrm{S}_{\mathrm{N}} 2$ (bimolecular nucleophilic substitution) chemistry; however, this reactivity has major limitations in complex molecular settings ${ }^{5}$. Indeed, while substitutions on primary substrates are easy to perform, extension to secondary and tertiary substrates is challenging due to their increased steric hindrance. The requirement for forcing conditions (strong bases, high temperatures) often results in low yields and leads to competitive E2-elimination to alkene by-products. The intrinsic difficulties in $\mathrm{S}_{\mathrm{N}} 2$ reactivity are underscored by the fact that, among all the $\mathrm{N}$-nucleophilic substitutions reported in the literature, $93 \%$ take place on primary alkyl halides and only $6 \%$ and $1 \%$ involve secondary and tertiary substrates, respectively (Fig. $1 \mathrm{~b}$ and Supplementary Fig. 30). Furthermore, the limited pool of substitutions at secondary centres is largely biased towards the use of activated electrophiles (for example, benzylic, $\alpha$-carbonyl), making the frequency of nucleophilic displacement at unactivated secondary halides $<1.5 \%$. As a result, the preferred route to assemble $\mathrm{C}-\mathrm{N}$ bonds on secondary $s p^{3}$ centres is largely based on the use of ketones via reductive aminations ${ }^{6,7}$, but this is only feasible for the reaction of alkylamines and cannot be extended to other valuable $N$-nucleophiles such as azoles, amides and carbamates.

The limitations of these polar approaches have recently triggered the exploration of alternative reactivity modes based on radical chemistry. In this context, copper catalysis has demonstrated a unique versatility in orchestrating coupling reactions involving carbon-radical intermediates ${ }^{5,8}$. The success of these transformations generally relies on the ability of $\mathrm{Cu}(\mathrm{II})$ complexes to trap carbon radicals at near diffusion-controlled rates ${ }^{9}$, and then undergo facile reductive elimination from the resulting high-valent $\mathrm{Cu}(\mathrm{III})$ species ${ }^{10}$. The potential of these two elementary steps to assemble a broad array of $s p^{3} \mathrm{C}-\mathrm{Y}$ bonds $(\mathrm{Y}=\mathrm{C}, \mathrm{N}, \mathrm{O}, \mathrm{S}$, halogen) represents a powerful opportunity for modular fragment coupling ${ }^{11}$.

Despite these prominent features, copper catalysis has seen limited applications to the amination of unactivated alkyl halides ${ }^{12,13}$. As shown in Fig. 1c, the overall amination using a [Cu(I)-amido] species would require initial single-electron transfer (SET) reduction of the halide, followed by radical capture to give the [alkyl$\mathrm{Cu}(\mathrm{III})$-amido] complex that undergoes fast reductive elimination. Although radical recombination and reductive elimination are very facile, the low reduction potential of unactivated alkyl halides $\left(E_{\text {red }}<-2 \mathrm{~V}\right.$ versus saturated calomel electrode (SCE)) thwarts their activation by $\mathrm{Cu}(\mathrm{I})$, ultimately limiting synthetic applications. This lack of reactivity contrasts with the ubiquitous applicability of activated substrates, such as $\alpha$-carbonyl and benzylic halides ${ }^{14,15}$, that are much easier to reduce $\left(E_{\text {red }}>-1.5 \mathrm{~V}\right.$ versus SCE) and therefore readily engage in $\mathrm{Cu}$-catalysis.

In an effort to address this issue, two main approaches have emerged in recent years, both relying on the use of photochemistry to aid the radical generation step. Fu and Peters reported pioneering works using photochemistry to engage unactivated alkyl and aryl halides in $\mathrm{C}-\mathrm{N}$ bond formations ${ }^{16-18}$. In these examples, photoexcitation of the transient amido-Cu(I) complex (amido $=$ carbazole, indole, amide) is required to access a highly reducing species from which SET reduction of the organic halides is possible. This strategy, which hinges on the photochemical performance of the amido- $\mathrm{Cu}(\mathrm{I})$ complex and is therefore highly dependent on the $N$-nucleophile structure, activates the alkyl halide by SET and often requires high-energy UV-light irradiation $(h \nu=254 \mathrm{~nm})^{19}$.

An alternative avenue for copper-catalysed aminative cross-coupling relies on the combination with visible-light photoredox catalysis and the use of carboxylic acids or their activated derivatives as alkyl radical precursors ${ }^{20-22}$. In these cases, radical generation by SET reduction is facile $\left(E_{\text {red }}>-1.5 \mathrm{~V}\right.$ versus SCE), but the extension of this approach to unactivated alkyl halides is challenging.

'Department of Chemistry, University of Manchester, Manchester, UK. ²Early Chemical Development, Pharmaceutical Sciences R\&D, AstraZeneca, Macclesfield, UK. ${ }^{3} T h e s e$ authors contributed equally: Bartosz Górski, Anne-Laure Barthelemy. ${ }^{凶}$-mail: fabio.juliahernandez@manchester.ac.uk; daniele.leonori@manchester.ac.uk 


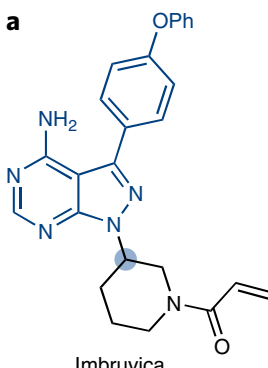

Imbruvica

Anticancer<smiles>C[C@H]1CCN(C(=O)CC#N)CC1N(C)c1ncnc2[nH]ccc12</smiles>

Xeljanz

Immunosuppressant<smiles>CN1C2CCC1CC(NC(=O)c1nn(C)c3ccccc13)C2</smiles><smiles>CC1(O)CCCCC1</smiles>

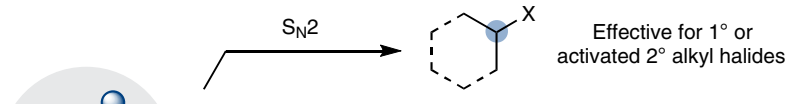

Effective for $1^{\circ}$ or activated $2^{\circ}$ alkyl halides

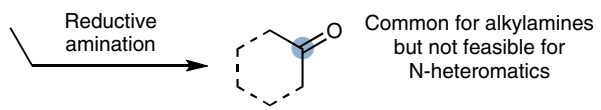

b

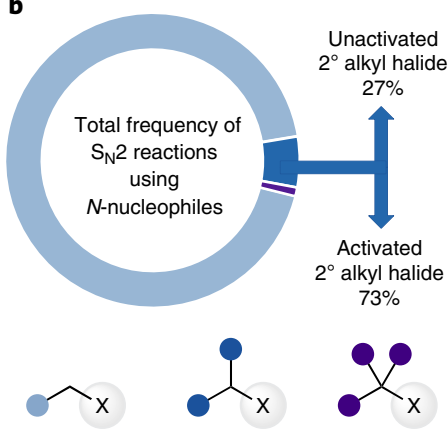

Primary: $93 \%$ Secondary : $6 \%$ Tertiary: $1 \%$<smiles>IC1CCCCC1</smiles>

Kytril

Antiemetic

Fig. 1 Relevance and assembly of $\mathbf{s p}^{\mathbf{3}} \mathbf{C}-\mathbf{N}$ bonds. a, Molecules containing $s p^{3} \mathrm{C}-\mathrm{N}$ bonds are widespread among many high-value materials. However, these bonds are still challenging to assemble. $\mathbf{b}$, Analysis of substitution reactions involving $N$-nucleophiles and alkyl halides. c, The use of copper catalysis in the amination of unactivated alkyl halides is hampered by the initial SET reduction. Here we demonstrate that XAT using $\alpha$-aminoalkyl radicals can be used to bypass this issue and enable catalytic $s p^{3} \mathrm{C}-\mathrm{N}$ bond formation.

Overall, the limited capacity to access strong reducing species remains the key element restricting general application of copper catalysis in amination chemistry. From this perspective, a strategy able to circumvent the problematic alkyl halide SET reduction, while still benefitting from the ability of copper to forge $s p^{3} \mathrm{C}-\mathrm{N}$ bonds by reductive elimination, might provide a powerful tool towards achieving the assembly of complex nitrogenated motifs.

Recently, ourselves ${ }^{23,24}$ and the group of Doyle ${ }^{25,26}$ have demonstrated that alkyl radicals can be accessed from the corresponding halides by exploiting the ability of $\alpha$-aminoalkyl radicals to trigger halogen-atom-transfer (XAT) reactions. This blueprint for radical generation is facilitated by the interplay of strong polar effects in the transition state of the halide abstraction $\operatorname{step}^{27}$ and can be used as part of $\mathrm{C}-\mathrm{C}$ bond-forming strategies such as Giese alkylation and Heck-type olefination. We recently questioned if this reactivity mode could be integrated with copper catalysis to enable $s p^{3} \mathrm{C}-\mathrm{N}$ bond formation. Such a strategy would benefit from a carbon-halogen bond-activation step occurring outside the copper cycle, independently from the nature of the $N$-nucleophile and also obviating for the need for additional photocatalysis.

In this Article, we describe the successful realization of this proposal and demonstrate that integration of $\alpha$-aminoalkyl-mediated XAT with copper catalysis is a practical and effective tool to achieve the amination of secondary alkyl iodides. This mode for $s p^{3} \mathrm{C}-\mathrm{N}$ bond formation is fast, operates under mild conditions, display broad functional group tolerance and can be used in the late-stage functionalization of complex bioactive materials.

\section{Results}

Reaction design and optimization. A detailed description of the reaction design for this XAT-Cu-mediated amination is provided in Fig. 2a using the coupling of 4 -iodo-N-Boc-piperidine 1 with 3-chloroindazole 2 . Starting with a $\mathrm{Cu}(\mathrm{I})$ catalyst, base-aided azole coordination is expected to afford the $[\mathrm{Cu}(\mathrm{I})-2]$ complex $\mathbf{A}$. At this stage, we postulated that the known ground-state SET between $\mathrm{Cu}(\mathrm{I})$ and a peroxide $\mathbf{B}$ could be used to simultaneously obtain a [Cu(II)-2] complex $\mathbf{C}$ and an electrophilic O-radical, $\mathbf{D}^{28}$. This species would have the appropriate philicity and reactivity profile to undergo HAT selectively at the $\alpha-N$ position of alkyl amine $\mathbf{E}^{29}$. The activated nature (bond-dissociation energy $\left.(\mathrm{BDE})=91 \mathrm{kcal} \mathrm{mol}^{-1}\right)^{30}$ and hydridic character of this $\mathrm{C}-\mathrm{H}$ bond should lead to a polarity-matched process resulting in the $\alpha$-aminoalkyl radical $\mathbf{F}$. This species is the key agent for the homolytic activation of iodide $\mathbf{1}$ through XAT and would generate the alkyl radical G (and iminium $\mathbf{H})$. At this point, fast capture of radical $\mathbf{G}$ by $\mathbf{C}$ would provide the high-valent [alkyl-Cu(III)-2] species I from which reductive elimination is facile. This last step would forge the targeted $s p^{3} \mathrm{C}-\mathrm{N}$ bond in 3 and regenerate the $\mathrm{Cu}(\mathrm{I})$ catalyst.

The realization of this approach is not without challenges, as it requires the synchronized interplay of SET $\rightarrow \mathrm{HAT} \rightarrow \mathrm{XAT}$ steps. Indeed, examination of this mechanistic pathway revealed three major aspects potentially hampering reactivity. Because $\alpha$-aminoalkyl radicals are electron-rich species $\left(E_{\mathrm{ox}} \approx-1.1 \mathrm{~V}\right.$ versus $\mathrm{SCE})^{29}$, XAT needs to be faster than both oxidation of $\mathbf{F}$ by peroxide $\mathbf{B}$ (leading to $\mathbf{H}$ ) and also capture of $\mathbf{F}$ by the $\mathrm{Cu}(\mathrm{II})$ species $\mathbf{C}$, which would result in aminal-type by-products (Supplementary Figs. 27 and 28). Furthermore, radical capture of alkyl radical $\mathbf{G}$ by $\mathbf{C}$ needs to outcompete a potential $\mathrm{H}$-abstraction from amine $\mathbf{E}$, which would result in dehalogenation (Supplementary Fig. 29).

With this mechanistic picture in mind, the model reaction between iodide $\mathbf{1}$ and azole $\mathbf{2}$ was evaluated. After screening of reaction conditions, we identified an effective protocol leading to the formation of 3 in high yield in just $1 \mathrm{~h}$ at room temperature (Fig. 2b). This process uses $\left[\mathrm{Cu}\left(\mathrm{CH}_{3} \mathrm{CN}\right)_{4}\right] \mathrm{PF}_{6}$ as the catalyst, $n-\mathrm{Bu}_{3} \mathrm{~N}$ 
a

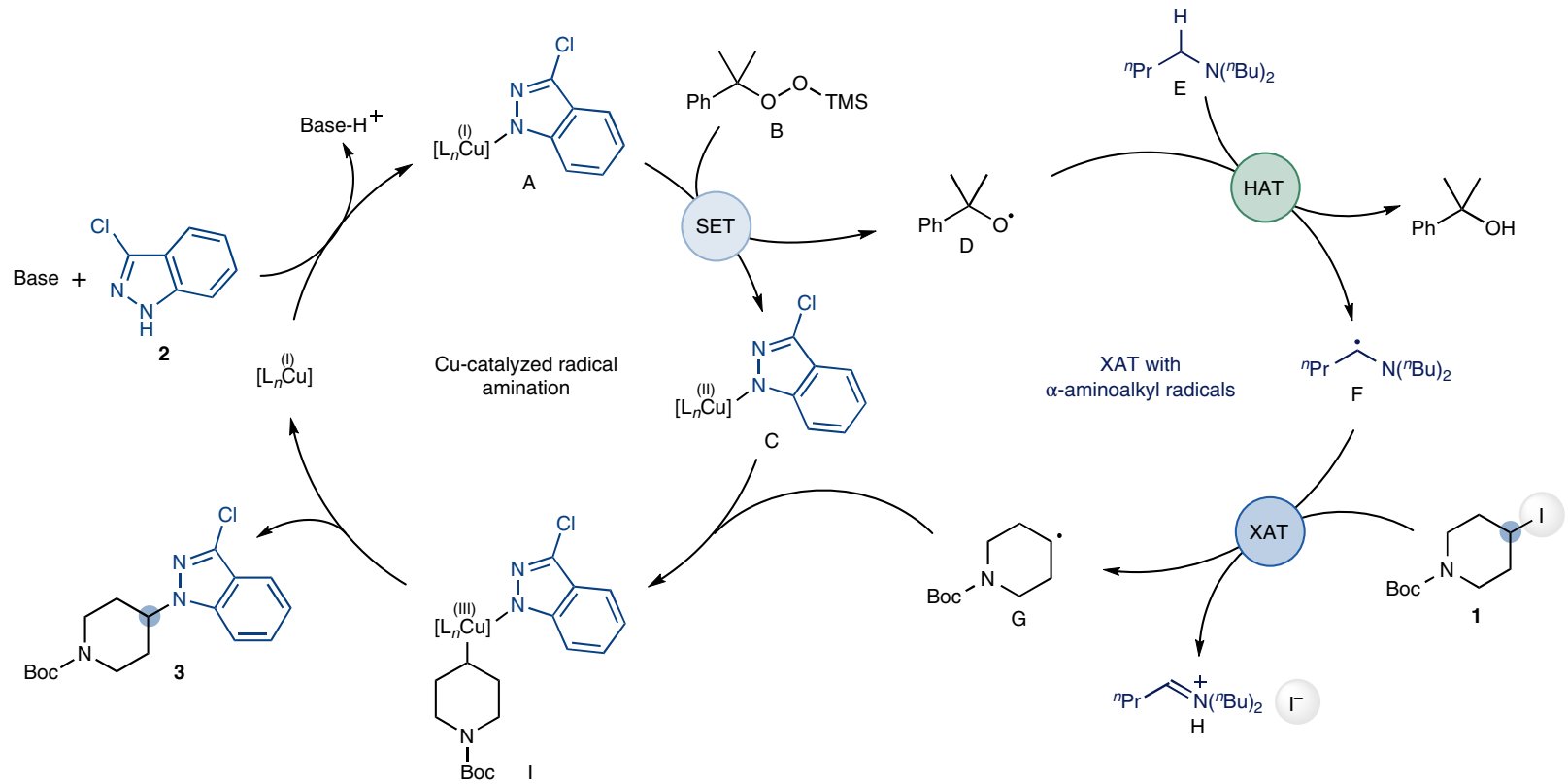

b<smiles>CC(C)(C)OC(=O)N1CCC(Cl)CC1</smiles>
$\stackrel{2}{2}$ (1.5 equiv.)

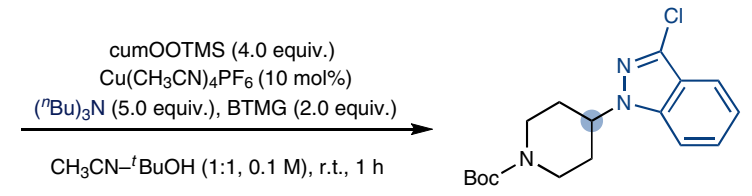

3<smiles>c1ccc2c(c1)Cc1ccccc1C2</smiles><smiles>CCOC(=O)C1=C(C)NC(C)=C(C(=O)OCC)C1</smiles>

\begin{tabular}{|c|c|c|c|c|c|c|c|c|}
\hline Entry & Variations & Yield (\%) & Entry & Variations & Yield (\%) & Entry & Variations & Yield (\%) \\
\hline 1 & None & 74 & 5 & No BTMG & - & 9 & $\left(\mathrm{Me}_{3} \mathrm{Si}\right)_{3} \mathrm{SiH}$ instead of $\left({ }^{n} \mathrm{Bu}\right)_{3} \mathrm{~N}$ & 20 \\
\hline 2 & $\mathrm{No}\left[\mathrm{Cu}(\mathrm{MeCN})_{4}\right] \mathrm{PF}_{6}$ & - & 6 & $\mathrm{Et}_{3} \mathrm{~N}$ instead of $\left({ }^{n} \mathrm{Bu}\right)_{3} \mathrm{~N}$ & 68 & 10 & Reaction on $20 \mathrm{mmol}$ & 59 \\
\hline 3 & No cumOOTMS & - & 7 & DABCO instead of $\left({ }^{n} \mathrm{Bu}\right)_{3} \mathrm{~N}$ & - & 11 & Additive $=\mathbf{4}$ (5.0 equiv.) & - \\
\hline 4 & No $\left({ }^{n} \mathrm{Bu}\right)_{3} \mathrm{~N}$ & - & 8 & $T=0^{\circ} \mathrm{C}$ instead of r.t. & 70 & 12 & Additive $=\mathbf{5}$ (5.0 equiv.) & - \\
\hline
\end{tabular}

C
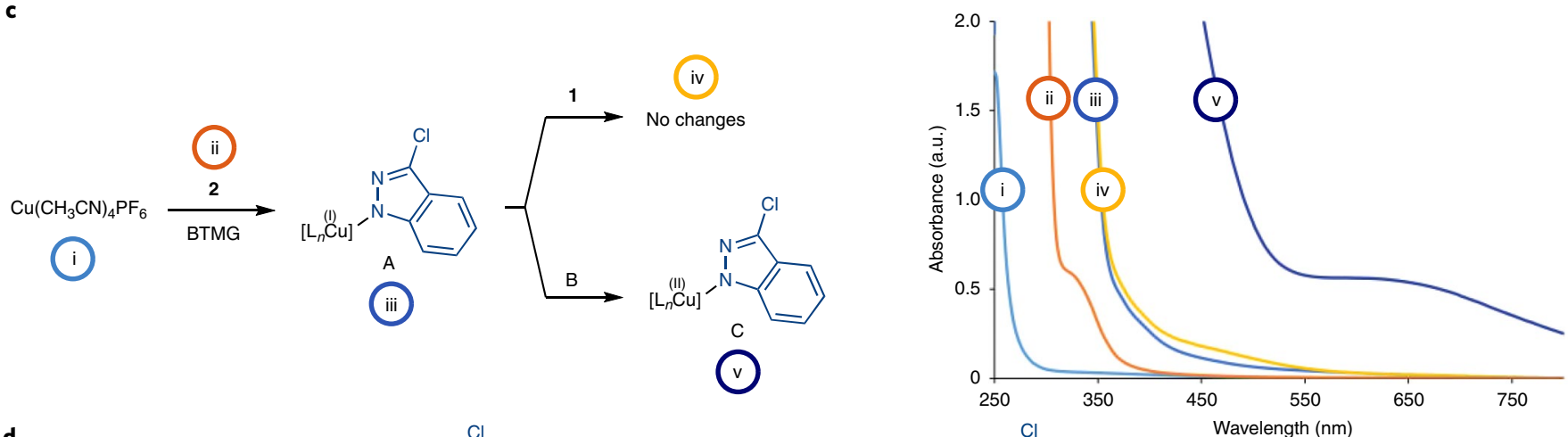

d

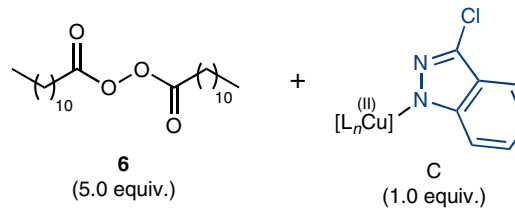

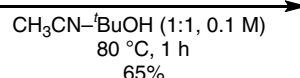

$65 \%$

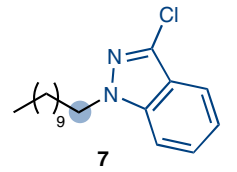

7

Fig. 2 | Development of a coupling between alkyl iodides and $\mathbf{N}$-nucleophiles by merging XAT and copper catalysis. a, The proposed mechanism for the amination of secondary alkyl iodides requires the merging of copper catalysis and XAT reactivity. $\mathbf{b}$, Optimization of the amination process between iodide 1 and $\mathrm{N}$-nucleophile $\mathbf{2}$ and relevant control reactions. c, UV-vis absorption spectroscopy studies support the individual steps in the catalytic cycle. d, Experiments probing the ability of alkyl radicals to undergo amination by reacting with [Cu(II)-N-nucleophile] species.

as the $\alpha$-aminoalkyl radicalprecursor, trimethylsilyl(TMS)-protected cumyl peroxide (cumOOTMS) as the oxidant and BTMG (2-tert-butyl-1,1,3,3-tetramethylguanidine) as the base $\left(\mathrm{p} K_{\mathrm{a}}=26.5\right)$ in $\mathrm{CH}_{3} \mathrm{CN}-t-\mathrm{BuOH}$ solvent. Full details on the optimization are discussed in the Supplementary Methods, but some experiments were of high relevance. Control reactions demonstrated that all components (copper catalyst, amine, oxidant and base) were required to obtain the product (entries 2-5, Fig. 2b). Although $n-\mathrm{Bu}_{3} \mathrm{~N}$ 


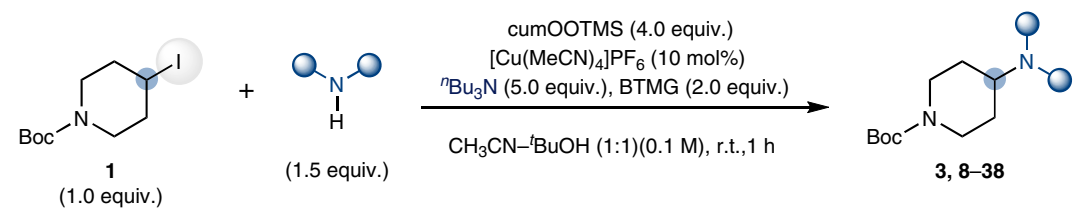<smiles>CC(C)(C)OC(=O)N1CCC(n2nc(Cl)c3ccccc32)CC1</smiles>

3
$74 \%$<smiles>CC(C)(C)OC(=O)N1CCC(n2ncc3ccccc32)CC1</smiles><smiles>Cc1nn(C2CCN(C(=O)OC(C)(C)C)CC2)c2ccccc12</smiles><smiles>CC(C)(C)OC(=O)N1CCC(n2nc(Br)c3ccccc32)CC1</smiles><smiles>CC(=O)c1nn(C2CCN(C(=O)OC(C)(C)C)CC2)c2ccccc12</smiles><smiles></smiles><smiles>Cc1ccc2c(ccn2C2=CCCCC2)c1</smiles><smiles>COc1ccc2c(ccn2C2CCN(C(=O)OC(C)(C)C)CC2)c1</smiles><smiles></smiles><smiles>CC(=O)OC(C)(C)OC(=O)N1CCC(n2cc(CC(NC(=O)OC(C)(C)C)C(=O)OCc3ccccc3)c3ccccc32)CC1</smiles><smiles>CC(C)(C)OC(=O)N1CCC(n2cc(C(N)=O)c3ccccc32)CC1</smiles><smiles>CC(C)(C)OC(=O)N1CCC(n2c3ccccc3c3ccccc32)CC1</smiles><smiles>CC(C)(C)OC(=O)N1CCC(=C2CCCCC2)CC1</smiles><smiles>CC(C)(C)OC(=O)N1CCC(=C2N=Cc3cnc(Cl)nc32)CC1</smiles><smiles>CC(C)(C)OC(=O)N1CCC(Nc2ccccn2)CC1</smiles><smiles>COc1ccnc(NC2CCN(C(=O)OC(C)(C)C)CC2)c1</smiles><smiles>CC(C)(C)OC(=O)N1CCC(=Nc2cc(F)ccn2)CC1</smiles><smiles>Cc1ccc(NC2CCN(C(=O)OC(C)(C)C)CC2)nc1</smiles><smiles>CC(C)(C)OC(=O)N1CCC(Nc2ccc(C(F)(F)F)cn2)CC1</smiles><smiles>CC(C)(C)OC(=O)N1CCC(=Nc2ccc(Br)cn2)CC1</smiles><smiles>CC(C)(C)OC(=O)N1CCC(=C2CCCCC2)CC1</smiles><smiles>CC(C)(C)OC(=O)N1CCC(=C2CCCCC2N(c2ccccc2)c2ccccn2)CC1</smiles><smiles>CC(C)(C)OC(=O)N1CCC(Nc2ccc3ccccc3n2)CC1</smiles><smiles>CC(C)(C)OC(=O)N1CCC(=CNc2ncccn2)CC1</smiles><smiles>CC(C)(C)OC(=O)N1CCC(=Nc2ncc(I)cn2)CC1</smiles>
$\underset{61 \%}{27}$

28

29
$48 \%$

30
$77 \%$

31
$47 \%$ b,c,d<smiles>CC(C)(C)OC(=O)N1CCC(Nc2nccc(-c3ccccc3)n2)CC1</smiles><smiles>CC(C)(C)OC(=O)N1CCC(Nc2cnccn2)CC1</smiles><smiles>CC(C)(C)OC(=O)N1CCC(Nc2ncnn3cccc23)CC1</smiles><smiles>O=C(c1ccccc1)N1CCC(=NC(c2ccccc2)c2ccccc2)CC1</smiles><smiles>CC(C)(C)OC(=O)N1CCC(N)CC1</smiles>

32
$51 \%$ b,c

33

$43 \%$, c

34
$73 \%$

35
$52 \%$

36
Quant.<smiles>CC(C)(C)OC(=O)N1CCC(=C2CCCC2N2CCOC2=O)CC1</smiles>

37
$62 \%$<smiles>CC(C)(C)OC(=O)N1CCC(N2CCC2=O)CC1</smiles>

$98 \%{ }^{\mathrm{b}}$
Unsuccessful $\mathrm{N}$-nucleophiles:<smiles>CC(C)(C)OC(=O)N1CCC(Nc2ccccc2)CC1</smiles>

39

40

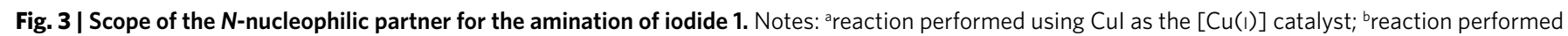
using $\mathrm{CuCl}$ as the $[\mathrm{Cu}(\mathrm{I})]$ catalyst; creaction performed at $0^{\circ} \mathrm{C}$; ${ }^{d}$ reaction performed using $\mathrm{DMF}-\mathrm{CH}_{3} \mathrm{CN}(9: 1)$ as the solvent. Boc, $t$-butyloxycarbonyl.

provided the highest reaction yield, other amines were compatible as long as they led to the generation of an $\alpha$-aminoalkyl radical (entries 6 and 7). The coupling was also efficient at $0^{\circ} \mathrm{C}$ (entry 8 ), which is in contrast with the high temperatures $\left(T>100^{\circ} \mathrm{C}\right)$ generally required in processes based on $\mathrm{Cu}$ /peroxide systems for $s p^{3}$ $\mathrm{C}-\mathrm{H}$ functionalization ${ }^{31,32}$. Finally, the use of supersilane ${ }^{33}$, which is frequently adopted as XAT reagent in both classical radical chemistry as well as modern photoredox-based approaches ${ }^{34}$, resulted in low yields owing to competitive dehalogenation (entry 9).

In terms of reproducibility and scalability, the process was insensitive to the presence of water and was run in the laboratory of AstraZeneca up to multi-gram scale $(20 \mathrm{mmol})$, providing similar 


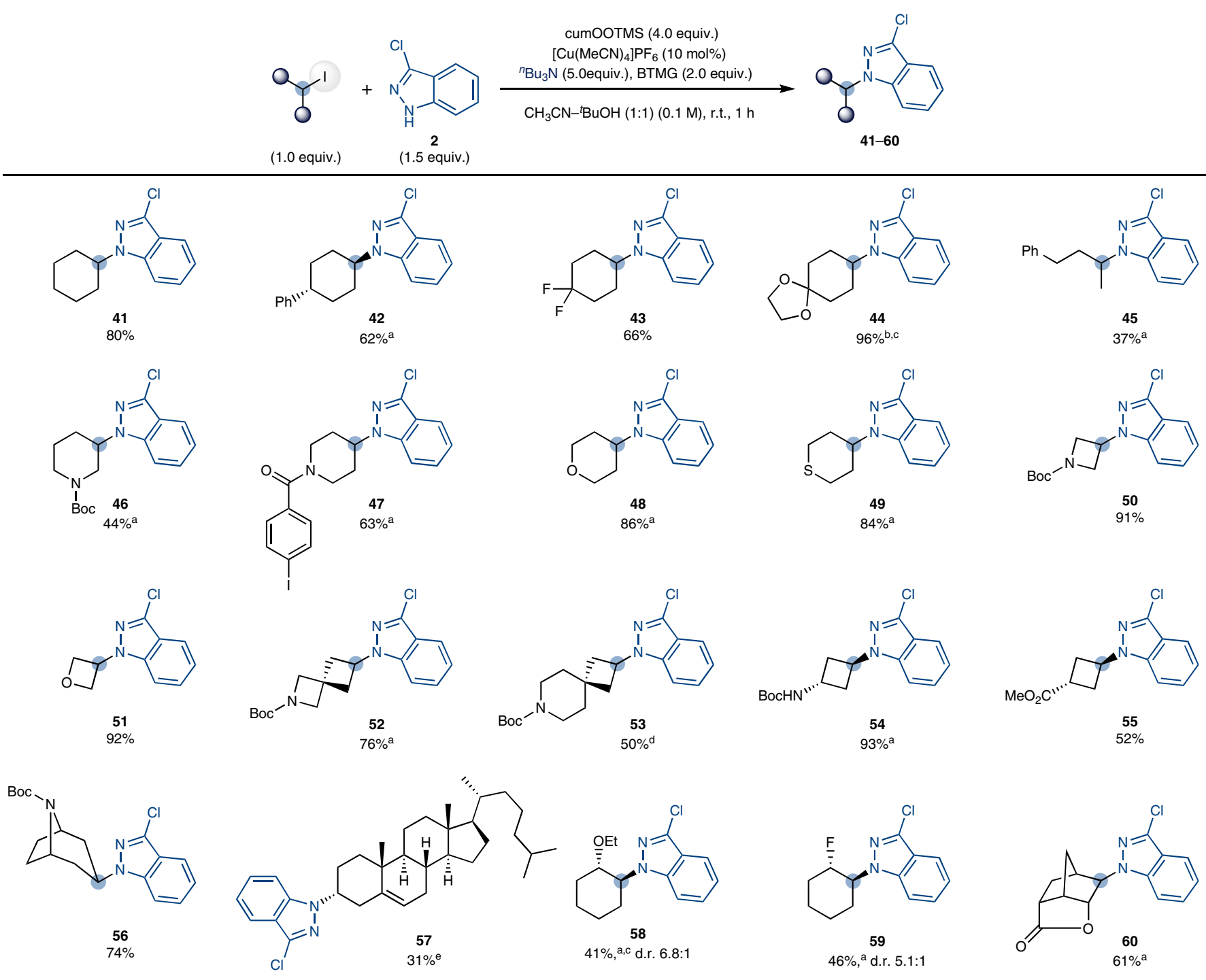

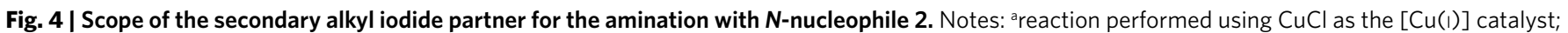
${ }^{b}$ reaction performed using $\mathrm{Cul}$ as the $[\mathrm{Cu}(\mathrm{I})]$ catalyst; ${ }^{\mathrm{c}}$ reaction performed at $\mathrm{O}^{\circ} \mathrm{C}$; ${ }^{\mathrm{d}}$ reaction performed using $\mathrm{Cul}(1 \mathrm{~mol} \%)$ as the [Cu(I)] catalyst; ${ }^{\mathrm{e}}$ reaction performed using $\mathrm{CF}_{3}-\mathrm{C}_{6} \mathrm{H}_{5}: \mathrm{CH}_{3} \mathrm{CN}$ (9:1) as the solvent. Boc, $t$-butyloxycarbonyl; d.r., diastereomeric ratio.

yields of 3 (entry 10). Peroxides are often problematic reagents due to their potentially exothermic decomposition. Before scale-up, safety assessments performed at AstraZeneca demonstrated that cumOOTMS can be handled safely and does not have explosive properties (differential scanning calorimetry analysis showed an exotherm at $T>107^{\circ} \mathrm{C}$ ), thus alleviating the initial concerns associated with the scale-up of this methodology (Supplementary Methods).

Mechanistic studies. Under our reaction conditions, $\alpha$-aminoalkyl radical $\mathbf{F}$ is generated by $\mathrm{HAT}$ on $n-\mathrm{Bu}_{3} \mathrm{~N}$. The inclusion of additives with weaker and hydridic $\mathrm{C}-\mathrm{H}$ bonds should therefore interfere with this step and, by outperforming the amine in the reaction with $\mathbf{D}$, suppress the coupling process ${ }^{31}$. Indeed, when 5.0 equiv. of 9,10-dihydroanthracene $4\left(\mathrm{BDE}_{\mathrm{C}-\mathrm{H}}=76 \mathrm{kcalmol}^{-1}\right)^{35}$ or the Hantzsch ester $5\left(\mathrm{BDE}_{\mathrm{C}-\mathrm{H}}=69 \mathrm{kcal} \mathrm{mol}^{-1}\right)^{36}$ were incorporated, no product was detected and the alkyl iodide was largely recovered (Fig. 2b, entries 11 and 12). Together with the lack of reactivity observed when amines without $\alpha-\mathrm{NC}-\mathrm{H}$ bonds were employed (for example 1,4-diazabocyclo[2.2.2] octane, DABCO) (Supplementary Information), these competition experiments prove the fundamental role of $\mathbf{F}$ in the $\mathrm{C}-\mathrm{I}$ bond-activation step.
Next, we sought to use UV-vis absorption spectroscopy to obtain further information on some of the individual steps involved in the copper catalytic cycle (Fig. 2c). When a colourless solution of $\left[\mathrm{Cu}(\mathrm{MeCN})_{4}\right] \mathrm{PF}_{6}$ was treated with 2 in the presence of BTMG, a pale yellow solution was formed. The formation of $[\mathrm{Cu}(\mathrm{I})-2] \mathrm{A}$ was possible only in the presence of the base, as also confirmed by ${ }^{1} \mathrm{H}$ NMR spectroscopy (Supplementary Fig. 13). The addition of alkyl iodide 1 to this solution did not lead to any significant change in the UV-vis spectrum, and the foreseen lack of reactivity between $\mathbf{A}$ and $\mathbf{1}$ was also demonstrated by stoichiometric experiments (Supplementary Figs. 14 and 15). By contrast, addition of cumOOTMS resulted in an immediate colour change to dark green, which corresponded to the appearance of a new absorbance band centred at $\sim 600 \mathrm{~nm}$, matching those reported for other amido- $[\mathrm{Cu}(\mathrm{II})]$ complexes $^{37,38}$. This supports the formation of [Cu(II)-2] C, as further confirmed by comparison with a sample of $[\mathrm{Cu}(\mathrm{II})-2]$ complex (obtained by mixing $\mathrm{Cu}(\mathrm{OTf})_{2}+2+$ BTMG) (Supplementary Figs. 14 and 15).

Finally, to validate the last step of the copper catalytic cycle, we studied the stoichiometric reaction of $\mathbf{C}$ with alkyl radicals generated by thermal decomposition of lauroyl peroxide $\mathbf{6}$. As shown in Fig. 2d, the successful formation of 7 provides evidence supporting 

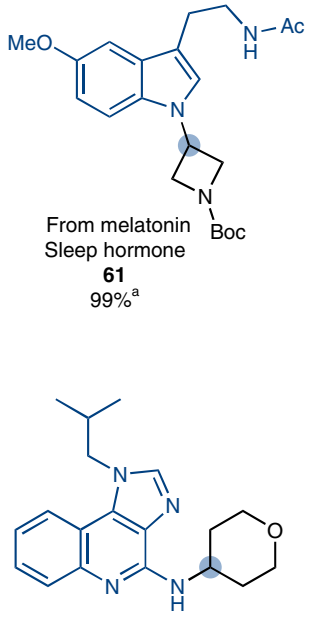

$$
\begin{gathered}
\text { From imiquimod } \\
\text { Treatment of carcinoma } \\
65 \\
98 \%{ }^{\mathrm{a}, \mathrm{c}}
\end{gathered}
$$
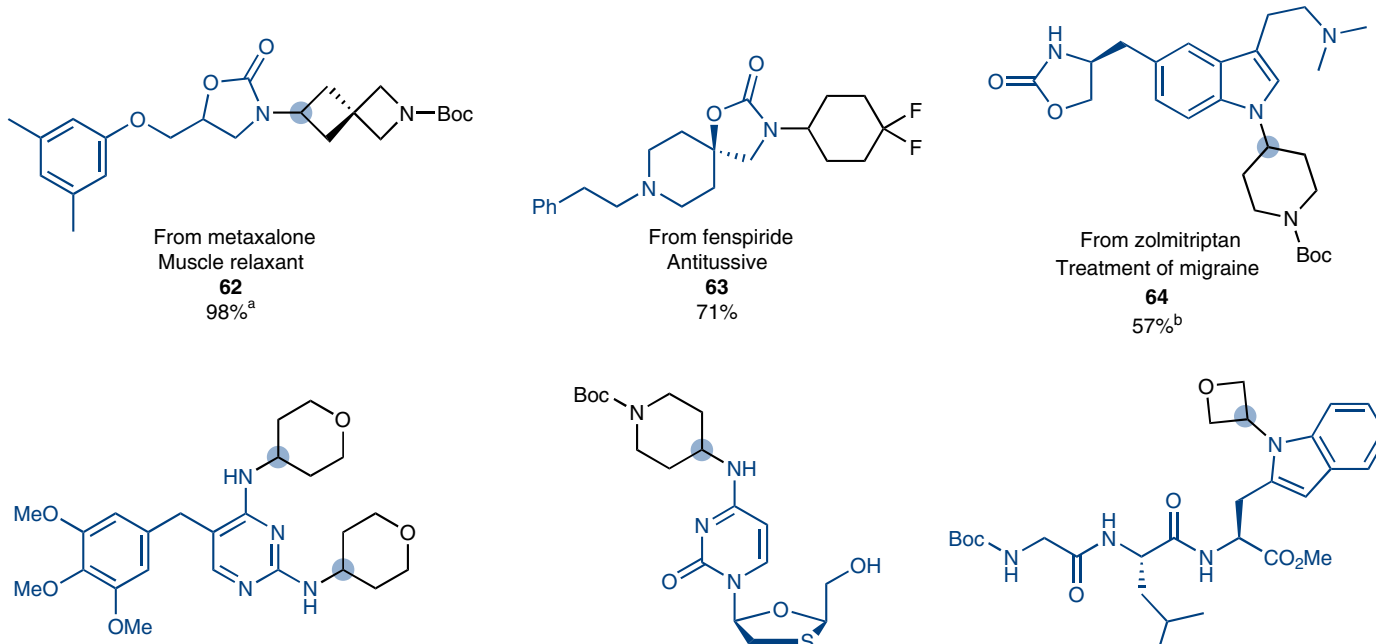

From trimethoprim Antibiotic 66

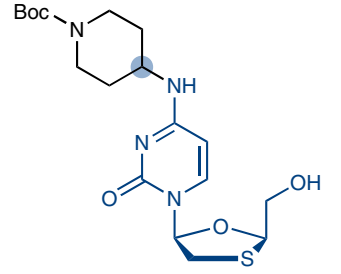

From lamivudine Antiretroviral 67

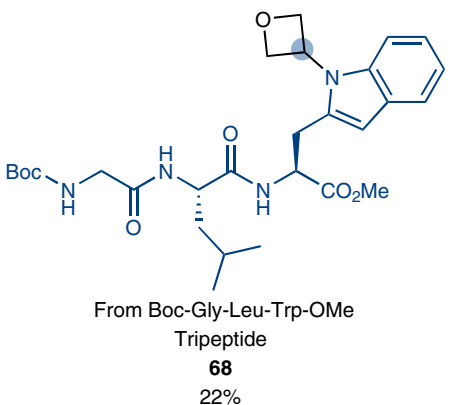

Fig. 5 | Late-stage $\mathbf{N}$-alkylations of complex and biologically active materials. Notes: areaction performed using $\mathrm{CuCl}$ as the $[\mathrm{Cu}(\mathrm{I})]$ catalyst; ${ }^{b}$ reaction

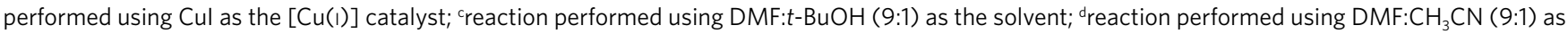
the solvent. Boc, $t$-butyloxycarbonyl.

the proposed radical metallation on [Cu(II)-2], followed by reductive elimination that complete our proposed mechanism for $s p^{3}$ $\mathrm{C}-\mathrm{N}$ bond assembly ${ }^{31}$.

Substrate scope. The optimized reaction conditions were then applied to a wide variety of $N$-nucleophiles using $\mathbf{1}$ as the coupling partner (Fig. 3). The $\mathrm{N}$-alkylation of azoles is still a recognized challenge in synthetic chemistry, so we were pleased to see that many systems were compatible with our process. This included differentially substituted indazoles (8-11) and indoles (12-15), which could incorporate handles for further cross-coupling, such as chloride, bromide and ester functionality. Pleasingly, we succeeded in alkylating a protected tryptophan residue (16) and also accessed 17, which is a synthetic intermediate for the preparation of the antineoplastic enzastaurin ${ }^{39}$. Carbazole (18) and pyrrole (19) could be used, as well as a functionalized 7-deazapurine (20), which is a common scaffold in many blockbuster drugs like pevonedistat (anticancer).

Aminopyridines are motifs frequently encountered in drug-development campaigns and could also be alkylated in high yields. Electronic (21-26) and steric (27) perturbation of the system did not hamper reactivity, and we also succeeded in using the less nucleophilic $N$-phenyl derivative (28). Other systems that underwent efficient coupling with 1 were 2 -aminoquinoline (29), several 2-amino-pyrimidines (30-32), 2-amino-pyrazine (33), as well as 2 -aminopyrrolo[2,1-f][1,2,4] triazine $(34)$, which is found in the structure of many commercial drugs, including remdesivir, an antiviral considered for the treatment of COVID-19 infections ${ }^{40}$.

We then considered the possibility of using this chemistry to convert alkyl iodides into primary amines, something challenging with ammonia owing to known over-alkylation issues. Pleasingly, we could engage commercially available benzophenoneimine ${ }^{41,42}$ as an effective surrogate providing $\mathbf{3 5}$, which, upon simple deprotection, gave primary amine $\mathbf{3 6}$.

The use of carbamates/amides in this coupling process proved difficult (see below), but we nonetheless demonstrate efficient alkylation of a cyclic carbamate (37), as well as a $\beta$-lactam that gave $\mathbf{3 8}$ in near quantitative yield.

The Supplementary Discussion contains information regarding additional control experiments run with each class of nucleophiles to rule out background $\mathrm{S}_{\mathrm{N}} 2$ reactivity (Supplementary Tables 2, 5, 6 and 7). In all cases, no product formation was detected when the reactions were run in the absence of copper catalyst and oxidant.

Our scope evaluation demonstrated wide compatibility with many classes of $\mathrm{N}$-reagents, notoriously difficult in classical $\mathrm{S}_{\mathrm{N}} 2$ settings. In terms of limitations, we did not succeed in extending this chemistry to less nucleophilic benzamide (for example, 39) and aniline (40). UV-vis absorption spectroscopy studies were therefore conducted to understand and identify the recalcitrant step in the copper catalytic cycle that was thwarting reactivity. In general, coordination of the $\mathrm{N}$-nucleophile to $\mathrm{Cu}(\mathrm{I})$ and/or the oxidation of the resulting species are currently believed to be the limiting steps, potentially resulting in unproductive pathways for the alkyl iodide, such as dehalogenation or elimination (Supplementary Figs. 22-26). This lack of reactivity has, however, provided a substantial opportunity for the chemoselective alkylation of complex materials (see below) that would have been very challenging using ionic approaches.

The alkyl iodide scope was evaluated using $\mathbf{2}$ as the nucleophile, and our conditions proved general for a broad array of substrates (Fig. 4a). Both cyclic and acyclic systems were successfully engaged, as demonstrated by the formation of 41-45, which also contain HAT-activated benzylic and $\alpha$-O positions. Several heterocyclic building blocks were evaluated and this included protected 3- and 4-iodo-piperidines (46 and 47), which increased the number of functionalities tolerated. Notably, the chemoselective activation of alkyl versus aryl iodides is demonstrated in 47 , which would be difficult by other strategies based on either SET or metal-mediated oxidative addition. This method also enabled coupling of 2 with 4-iodo(thio)pyranes (48 and 49), 2-iodo- $N$-Boc-azetidine (50) and 2-iodo-oxetane (51). Spirocyclic fragments ${ }^{43}$ are now popular in medicinal chemistry campaigns to increase the $s p^{3}$ content in organic leads ${ }^{44}$, and our methodology successfully led to the formation of $\mathbf{5 2}$ and $\mathbf{5 3}$ in good yield, while 3-substitued cyclobutyl iodides gave $\mathbf{5 4}$ and 55 .

The majority of alkyl iodides used in the scope are commercial building blocks. However, a powerful application was found by the preparation of nitrogenated scaffolds exploiting secondary alcohols via the Appel reaction and several olefins after iodo-functionalizations. For example, hydroxyl group-containing alkaloid nortropine and 
$3 \alpha$-cholestane were used to obtain indazole products 56 and 57 as single diastereomers. Furthermore, iodo-etherification and -fluorination of cyclohexene enabled formation of valuable vicinal ether and $\mathrm{F}$ derivatives 58 and 59, while iodolactonization then amination of norbornene carboxylic acid gave $\mathbf{6 0}$ in good yield. In all cases, the diasteroselectivity of the initial iodo-functionalization was inconsequential, as the substrates underwent stereoconvergent amination at the less hindered side. Hence, olefin iodo-functionalization represents a powerful gateway to quickly enlarge the pool of substrates available to this aminative coupling that cannot be accessed using, for example, radical strategies based on activated carboxylic acids.

Figure 5 depicts several examples of how this reaction can be applied at a late stage for the $\mathrm{N}$-alkylation of many complex bioactive materials. We succeeded in the selective and high-yielding alkylation of the indole ring in the sleep hormone melatonin in the presence of a tethered $N$-acetamide group (61). The oxazolidinone ring in metaxalone (62, a widely used muscle relaxant) and the antitussive fenspiride (63) were alkylated in high yield. The successful formation of $\mathbf{6 3}$ also demonstrates compatibility with tertiary amine functionalities, which are often problematic in photoredox catalysis. The migraine treatment medicine zolmitriptan is an interesting example because of the presence of both free indole and oxazolidinone. Our reaction conditions enabled a complete discrimination between these two nucleophilic sites, resulting in the chemoselective alkylation of the azole framework (64).

We then applied the method to the alkylation of complex 2 -aminopyridine- and 2-amino-pyridimidine-based drugs imiquimod and trimethoprim, which gave $\mathbf{6 5}$ and $\mathbf{6 6}$ in good to excellent yield. In the latter case, double alkylation of both nucleophilic $\mathrm{NH}_{2}$ groups was possible by increasing the equivalents of 4-iodopirane. Another example of chemoselective $\mathrm{N}$-alkylation is provided by the formation of $\mathbf{6 7}$ from the antiretroviral lamivudine. The success of this example is remarkable, as reactivity was exclusive at the 4-aminopyridinone core in the presence of a primary alcohol, two activated positions for HAT and a thioether. Finally, we obtained preliminary results demonstrating applicability of the coupling process in the alkylation of tryptophan residues in small peptides (68).

\section{Conclusions}

In summary, the integration of $\alpha$-aminoalkyl radical-mediated XAT with copper catalysis has led to the development of an efficient strategy for the coupling of secondary alkyl iodides with $N$-nucleophiles. The utilization of this strategy eliminates the requirement for strong reductants in the alkyl radical generation step. This reactivity occurs at room temperature under just $1 \mathrm{~h}$ and enables the preparation of many complex building blocks that are elusive through $\mathrm{S}_{\mathrm{N}} 2$ reactivity.

\section{Methods}

General procedure for the amination of alkyl iodides. An oven-dry tube equipped with a stirring bar was charged with the alkyl iodide $(0.20 \mathrm{mmol}$, 1.0 equiv. $)$, the $N$-nucleophile $(0.30 \mathrm{mmol}, 1.5$ equiv. $)$ and $\left[\mathrm{Cu}(\mathrm{MeCN})_{4}\right] \mathrm{PF}_{6}$ (7.5 $\mathrm{mg}, 0.020 \mathrm{mmol}, 10 \mathrm{~mol} \%$ ). The tube was capped with a Supelco aluminium crimp seal with septum (PTFE/butyl) and evacuated and refilled with $\mathrm{N}_{2}$ (three times). Dry and degassed $\mathrm{CH}_{3} \mathrm{CN}(1.0 \mathrm{ml}), t-\mathrm{BuOH}(1.0 \mathrm{ml}),(n-\mathrm{Bu})_{3} \mathrm{~N}(238 \mu \mathrm{l}$, $1.0 \mathrm{mmol}, 5.0$ equiv.), BTMG $(80 \mu \mathrm{l}, 0.40 \mathrm{mmol}, 2.0$ equiv. $)$ were sequentially added. The resulting solution was treated with cumOOTMS ( $224 \mathrm{mg}, 238 \mu \mathrm{l}$, $1.00 \mathrm{mmol}, 5.0$ equiv.) dropwise under vigorous stirring. After $1 \mathrm{~h}$ the tube was opened and the mixture diluted with brine $(2 \mathrm{ml})$ and EtOAc $(2 \mathrm{ml})$. The organic layer was separated and the aqueous layer was extracted with EtOAc $(5 \mathrm{ml} \times 2)$. The combined organic layers were dried $\left(\mathrm{MgSO}_{4}\right)$, filtered and evaporated. The crude material was purified by flash column chromatography on silica gel.

\section{Data availability}

The data supporting the findings of this study are available within the paper and its Supplementary Information or from the authors upon reasonable request.

Received: 11 January 2021; Accepted: 11 June 2021; Published online: 12 July 2021

\section{References}

1. Ricci, A. Amino Group Chemistry: From Synthesis to the Life Sciences (Wiley-VCH, (2008).

2. Vitaku, E., Smith, D. T. \& Njardarson, J. T. Analysis of the structural diversity, substitution patterns, and frequency of nitrogen heterocycles among U.S. FDA approved pharmaceuticals. J. Med. Chem. 57, 10257-10274 (2014).

3. Brown, D. G. \& Boström, J. Analysis of past and present synthetic methodologies on medicinal chemistry: where have all the new reactions gone? J. Med. Chem. 59, 4443-4458 (2016).

4. Trowbridge, A., Walton, S. M. \& Gaunt, M. J. New strategies for the transition-metal catalyzed synthesis of aliphatic amines. Chem. Rev. 120, 2613-2692 (2020).

5. Kaga, A. \& Chiba, S. Engaging radicals in transition metal-catalyzed cross-coupling with alkyl electrophiles: recent advances. ACS Catal. 7, 4697-4706 (2017).

6. Afanasyev, O. I., Kuchuk, E., Usanov, D. L. \& Chusov, D. Reductive amination in the synthesis of pharmaceuticals. Chem. Rev. 119, 11857-11911 (2019).

7. Kumar, R., Flodén, N. J., Whitehurst, W. G. \& Gaunt, M. J. A general carbonyl alkylative amination for tertiary amine synthesis. Nature 581, 415-420 (2020).

8. Hossain, A., Bhattacharyya, A. \& Reiser, O. Copper's rapid ascent in visible-light photoredox catalysis. Science 364, eaav9713 (2019).

9. Kochi, J. K. \& Subramanian, R. V. Kinetics of electron-transfer oxidation of alkyl radicals by copper(II) complexes. J. Am. Chem. Soc. 87, 4855-4866 (1965).

10. Casitas, A. \& Ribas, X. The role of organometallic copper(III) complexes in homogeneous catalysis. Chem. Sci. 4, 2301-2318 (2013).

11. Zhu, X. \& Chiba, S. Copper-catalyzed oxidative carbon-heteroatom bond formation: a recent update. Chem. Soc. Rev. 45, 4504-4523 (2016).

12. Jacobson, R. R., Tyeklár, Z. \& Karlin, K. D. Reaction of organic halides with [CuI(TMPA) $\left.\mathrm{CH}_{3} \mathrm{CN}\right] \mathrm{PF}_{6}$. Inorg. Chim. Acta 181, 111-118 (1991).

13. Cheng, L.-J. \& Mankad, N. P. C-C and C-X coupling reactions of unactivated alkyl electrophiles using copper catalysis. Chem. Soc. Rev. 49, 8036-8064 (2020).

14. Matsumoto, Y. et al. Amino acid Schiff base bearing benzophenone imine as a platform for highly congested unnatural $\alpha$-amino acid synthesis. J. Am. Chem. Soc. 142, 8498-8505 (2020).

15. Ishida, S., Takeuchi, K., Taniyama, N., Sunada, Y. \& Nishikata, T. Copper-catalyzed amination of congested and functionalized $\alpha$-bromocarboxamides with either amines or ammonia at room temperature. Angew. Chem. Int. Ed. 56, 11610-11614 (2017).

16. Bissember, A. C., Lundgren, R. J., Creutz, S. E., Peters, J. C. \& Fu, G. C. Transition-metal-catalyzed alkylations of amines with alkyl halides: photoinduced, copper-catalyzed couplings of carbazoles. Angew. Chem. Int. Ed. 52, 5129-5133 (2013).

17. Kainz, Q. M. et al. Asymmetric copper-catalyzed C-N cross-couplings induced by visible light. Science 351, 681-684 (2016).

18. Creutz, S. E., Lotito, K. J., Fu, G. C. \& Peters, J. C. Photoinduced Ullmann C-N coupling: demonstrating the viability of a radical pathway. Science 338 , 647-651 (2012)

19. Do, H.-Q., Bachman, S., Bissember, A. C., Peters, J. C. \& Fu, G. C. Photoinduced, copper-catalyzed alkylation of amides with unactivated secondary alkyl halides at room temperature. J. Am. Chem. Soc. 136, 2162-2167 (2014).

20. Mao, R., Frey, A., Balon, J. \& Hu, X. Decarboxylative $\mathrm{C}\left(s p^{3}\right)-\mathrm{N}$ cross-coupling via synergetic photoredox and copper catalysis. Nat. Catal. 1, 120-126 (2018).

21. Liang, Y., Zhang, X. \& MacMillan, D. W. C. Decarboxylative $s p^{3} \mathrm{C}-\mathrm{N}$ coupling via dual copper and photoredox catalysis. Nature 559, 83-88 (2018).

22. Nguyen, V. T. et al. Visible-light-enabled direct decarboxylative $\mathrm{N}$-alkylation. Angew. Chem. Int. Ed. 59, 7921-7927 (2020).

23. Constantin, T. et al. Aminoalkyl radicals as halogen-atom transfer agents for activation of alkyl and aryl halides. Science 367, 1021-1026 (2020).

24. Constantin, T. et al. A case of chain propagation: $\alpha$-aminoalkyl radicals as initiators for aryl radical chemistry. Chem. Sci. 11, 12822-12828 (2020).

25. Neff, R. K. et al. Generation of halomethyl radicals by halogen atom abstraction and their addition reactions with alkenes. J. Am. Chem. Soc. 141, 16643-16650 (2019)

26. $\mathrm{Su}, \mathrm{Y}$. L. et al. $\alpha$-Amino radical-mediated diverse difunctionalization of alkenes: construction of $\mathrm{C}-\mathrm{C}, \mathrm{C}-\mathrm{N}$ and $\mathrm{C}-\mathrm{S}$ bonds. ACS Catal. 10, 13682-13687 (2020).

27. Tedder, J. M. The importance of polarity, bond strength and steric effects in determining the site of attack and the rate of free radical substitution in aliphatic compounds. Tetrahedron 38, 313-329 (1982).

28. Kharasch, M. S. \& Sosnovsky, G. The reactions of $t$-butyl perbenzoate and olefins-a stereospecific reaction. J. Am. Chem. Soc. 80, 756-756 (1958).

29. Wayner, D. D. M., Dannenberg, J. J. \& Griller, D. Oxidation potentials of $\alpha$-aminoalkyl radicals: bond dissociation energies for related radical cations. Chem. Phys. Lett. 131, 189-191 (1986).

30. Lalevée, J., Allonas, X. \& Fouassier, J.-P. N-H and $\alpha(\mathrm{C}-\mathrm{H})$ bond dissociation enthalpies of aliphatic amines. J. Am. Chem. Soc. 124, 9613-9621 (2002). 
31. Tran, B. L., Li, B., Driess, M. \& Hartwig, J. F. Copper-catalyzed intermolecular amidation and imidation of unactivated alkanes. J. Am. Chem. Soc. 136 2555-2563 (2014).

32. Wang, C.-S., Wu, X.-F., Dixneuf, P. H. \& Soulé, J.-F. Copper-catalyzed oxidative dehydrogenative $\mathrm{C}\left(s p^{3}\right)-\mathrm{H}$ bond amination of (cyclo)alkanes using NH-heterocycles as amine sources. ChemSusChem 10, 3075-3082 (2017).

33. Chatgilialoglu, C., Ferreri, C., Landais, Y. \& Timokhin, V. I. Thirty years of (TMS) ${ }_{3} \mathrm{SiH}$ : a milestone in radical-based synthetic chemistry. Chem. Rev. 118, 6516-6572 (2018).

34. Zhang, P., Le, C. C. \& MacMillan, D. W. C. Silyl radical activation of alkyl halides in metallaphotoredox catalysis: a unique pathway for cross-electrophile coupling. J. Am. Chem. Soc. 138, 8084-8087 (2016).

35. Stein, S. E. \& Brown, R. L. Prediction of carbon-hydrogen bond dissociation energies for polycyclic aromatic hydrocarbons of arbitrary size. J. Am. Chem. Soc. 113, 787-793 (1991).

36. Zhu, X.-Q. et al. Determination of the $\mathrm{C} 4-\mathrm{H}$ bond dissociation energies of NADH models and their radical cations in acetonitrile. Chem. Eur. J. 9, 871-880 (2003).

37. Wiese, S. et al. Catalytic C-H amination with unactivated amines through copper(II) amides. Angew. Chem. Int. Ed. 49, 8850-8855 (2010).

38. Ahn, J. M., Ratani, T. S., Hannoun, K. I., Fu, G. C. \& Peters, J. C. Photoinduced, copper-catalyzed alkylation of amines: a mechanistic study of the cross-coupling of carbazole with alkyl bromides. J. Am. Chem. Soc. 139, 12716-12723 (2017).

39. Wang, M. et al. [11C]enzastaurin, the first design and radiosynthesis of a new potential PET agent for imaging of protein kinase C. Bioorg. Med. Chem. Lett. 21, 1649-1653 (2011).

40. Wang, Y. et al. Remdesivir in adults with severe COVID-19: a randomised, double-blind, placebo-controlled, multicentre trial. Lancet 395 , 1569-1578 (2020).

41. Mao, R., Balon, J. \& Hu, X. Cross-coupling of alkyl redox-active esters with benzophenone imines: tandem photoredox and copper catalysis. Angew. Chem. Int. Ed. 57, 9501-9504 (2018).

42. Peacock, D. M., Roos, C. B. \& Hartwig, J. F. Palladium-catalyzed cross coupling of secondary and tertiary alkyl bromides with a nitrogen nucleophile. ACS Cent. Sci 2, 647-652 (2016).
43. Carreira, E. M. \& Fessard, T. C. Four-membered ring-containing spirocycles: synthetic strategies and opportunities. Chem. Rev. 114, 8257-8322 (2014).

44. Lovering, F., Bikker, J. \& Humblet, C. Escape from Flatland: increasing saturation as an approach to improving clinical success. J. Med. Chem. 52, 6752-6756 (2009).

\section{Acknowledgements}

D.L. thanks EPSRC for a fellowship (EP/P004997/1) and a research grant (EP/ T016019/1) and the European Research Council for a research grant (758427). We thank W. Ashworth, P. Gillespie and S. Wells for performing safety studies. We thank M. Johansson (AstraZeneca) for useful discussions.

\section{Author contributions}

F.J. and D.L. designed the project and directed the work. B.G. and A.-L.B. performed all the synthetic and mechanistic experiments. J.J.D performed the scale-up experiments. All authors analysed the results and wrote the manuscript.

\section{Competing interests}

The authors declare no competing interests.

\section{Additional information}

Supplementary information The online version contains supplementary material available at https://doi.org/10.1038/s41929-021-00652-8.

Correspondence and requests for materials should be addressed to F.J. or D.L.

Peer review information Nature Catalysis thanks Michael Doyle and the other, anonymous, reviewer(s) for their contribution to the peer review of this work.

Reprints and permissions information is available at www.nature.com/reprints.

Publisher's note Springer Nature remains neutral with regard to jurisdictional claims in published maps and institutional affiliations.

(c) The Author(s), under exclusive licence to Springer Nature Limited 2021 